\title{
FISTULA LIQUÓRICA NASAL ESPONTÂNEA, SELA VAZIA E RESTOS DE ADENOMA HIPOFISÁRIO
}

\author{
Mario S. Cademartori *
}

As rinoliquorréias espontâneas em pacientes com sela túrcica vazia são de ocurrência rara. Obrador ${ }^{8}$ revisou a literatura recentemente encontrando apenas 9 casos. A sela vazia tem sido explicada por defeitos da embriogênese ósteo-dural etmoidal ${ }^{5}$, por hipertensão intracraniana de longa evolução ${ }^{10}$, por insuficiência do diafragma selar ${ }^{7}$, pela retirada cirúrgica de tumores hipofisários ou seu tratamento por procedimentos radioterápicos ou radioativos ${ }^{6}$ e, ainda, pelas grandes variaçōes volumétricas sofridas pela hipófise nos periodos gestacionais repetidos e na involunção ulterior ${ }^{1}$. Estes fatores, considerados como "potenciais", possibilitam a penetração do tecido sub-aracnóideo na sela túrcica ${ }^{1}$; a seguir, a pulsação do líquido cefalorraqueano, mesmo em pressão normal porém agindo continuadamente, terminaria erosando o plano ósseo do assoalho com eventual inicio da fístula.

Broughan e col. ${ }^{4}$ chamaram a atenção para a degeneração espontânea de tecido neoplásico que ocorreu em 12 casos de tumores hipofisários comprovada, em 10 casos, mediante necrópsia e suspeitada em dois pacientes que sobreviveram. Outros autores teoricamente admitem esta possibilidade ${ }^{3,7,8}$. Bernasconi e col. ${ }^{2}$ distinguem dois tipos de selas vazias: as de volume normal e as de volume aumentado. Quanto à etiologia admitem diferentes causas.

Justificamos a apresentação de um caso, por não termos encontrado referência a caso similar na literatura compulsada.

\section{OBSER V ACXO}

M.F.Q., paciente branca, com 39 anos de idade, solteira, internada no Hospital Cristo Redentor (Reg. 17567) em 19-4-1971. Há um ano a paciente vinha apresentando corrimento liquido, incolor, pela narina direita. Menarca aos 16 anos, menstruaçáo normal até os 20 anos quando, após episódio prolongado de intensa cefaléia fronto-occipital, passou a apresentar hipo, oligo e amenorréia. A partir de então seus cabelos comecaram a branquear. Há oito anos vem sofrendo de alopécia. Exame físico - Cabelos brancos e escassos e moderada obesidade. Exame clinico-neurológico - Nada foi registrado de anormal. A flexăo da cabeça determinava a saída de liquido límpido e incolor pela narina direita. O teste da glicofita no líquido nasal resultou em tranca positividade. Radiografias do cranio (Fig. 1) - Aumento das

Trabalho apresentado no IX Congresso Brasileiro de Neurocirurgia (Rio de Janeiro, GB; 1972): * Neurocirurgião do Instituto de Neurocirurgia de Porto Alegre. 

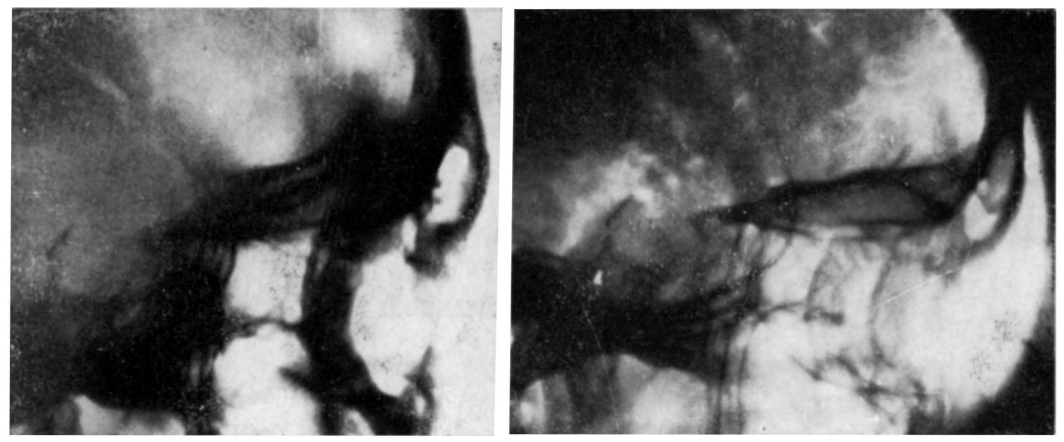

Fig. 1 - Caso $M . F: Q . \quad$ À esquerda, radiografia mostrando aumento das dimen. sões da sela túrcica e adelgaçamento do seu assoalho. ì direita pneumografia de perfil mostrando aeração intra-selar parcial.

dimensões da sela túrcica com adelgaçamento do assoalho. Pneumencefalografia (Fig. 1) - aeração intraselar parcial. Líquido cefalorraqueano: pressão e exame cito-químico normais. Provas de função hipofisária normais.

Em 26-4-1971 a paciente foi submetida a craniotomia frontal direita para correção da fístula liquórica. Na região óptico-quiasmática foi encontrado pequeno nódulo, aderido à face superior do nervo óptico direito e prolongando-se, por estreito filamento fibroso, para dentro da região selar. Não existia diafragma selar estando a sela túrcica invadida por leptomeninge e septos adelgaçados contendo líquido cefalorraqueano. A aste hipofísária estava bastante afilada. Foi feita dissecção cuidadosa destes tecidos, com saida de bastante líquido. Utilizando lentes foi possivel seguir a aste hipofisária rudimentar até a porção anterior e direita da sela, onde terminava em pequena proeminência achatada, em forma de disco, com pouco mais de um centímetro de diâmetro. Sua fina cápsula foi aberta, sendo colhidos pequenos fragmentos de tecido mole, de cor parda. Não foi visualisado o orifício fistuloso. A sela foi totalmente preenchida com fragmentos de músculo. No pós-operatório imediato e até o presente momento (20-1-73) não houve recidiva da fístula. Exame histopatológico (Fig. 2) - Nódulo extra-selar contendo células com citoplasma pouco corado pela eosina, núcleo redondo e leptocromático; hemorragia intra-tumoral e alterações celulares devidas à passagem de corrente elétrica pelo tecido; não foram encontradas atipias celulares. Hipófise apresentando dilatação capilar e células vacuoladas, não havendo invasão pelo processo neoplásico. Diagnóstico: adenoma cromófobo de hipófise.

\section{COMENTARIOS}

Acreditamos que no presente caso existem elementos para deduzir que a sela túrcica alargada e vazia foi primariamente deformada por um tumor hipofisário que, após ter crescido além dos limites selares, tenha sofrido involução parcial. Este fato é posto em evidência pelo fragmento remanescente do tumor implantado sobre o nervo óptico. Com ausência congênita ou secundária do diafragma, a cavidade selar ficou exposta às pulsões normais do líquido cefalorraqueano, adelgaçando-se o assoalho, ficando a fistulização sob o determinismo do acaso. 


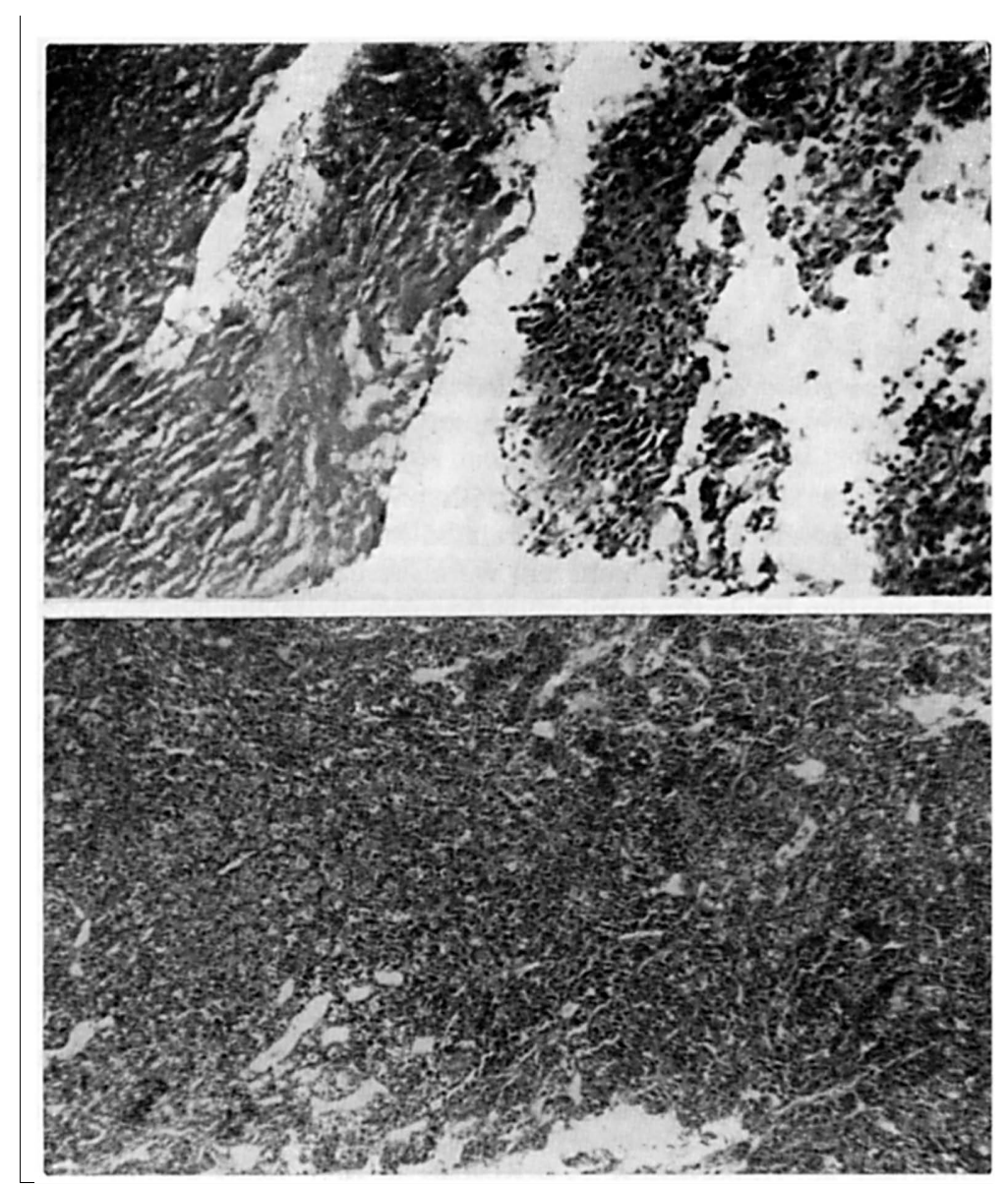

Fig. 2 - Caso M.F.Q. Na parte superior microfotografia do tecido extra-selar mostrando células com citoplasma pouco corado, núcleos redondos e hemorragia intra-tumoral (H.E. $100 \times)$. Na parte inferior microfotografia do tecido intra-selar, mostrando tecido hipofisário normal (H.E. $35 \times$ ).

\section{RES U M O}

É relatado o caso de uma paciente que, aos 20 anos de idade, após episódio de cefaléia fronto-occipital, entrou em amenorréia e, aos 39 anos, apresentou liquorréia nasal com um ano de duração. O estudo radiológico do crânio mostrou aumento das dimensões da sela túrcica. O pneumencefalograma mostrou aeração irregular da mesma. Durante a intervenção cirúrgica para correção da fístula, foram encontrados restos de tumor hipofisário sobre o nervo óptico direito; não existia diafragma selar, estando a cavidade 
selar preenchida por leptomeninge, liquido cefalorraqueano e pequena quantidade de tecido hipofisário no assoalho. O caso fornece razoáveis elementos que comprovam a hipótese de que a atrofia espontânea de tumor hipofisário possa ser considerada como uma das causas que explicam o fato da sela túrcica carecer de conteúdo normal.

\section{SUM M A R Y}

Spontaneous rhinorrhea, empty sella and residual pituitary adenoma: a case report

The case of a 39-years-old patient with an one-year duration rhinorrhea is reported. An headache episode was related at hers 20 years of life, followed by amenorrhea. The sella diameters were increased at X-rays examination and parcial aeration inside the turcic sella was seen by pneumoencephalography. Residual portion of pituitary adenoma was found over the right optic nerve during the surgical procedure. The turcic sella was filled by leptomeningeal tissue, cerebrospinal fluid and rests of pituitary tissue. No sellar diaphragm was seen. This case fournishes creditable elements to the assumption that the so-called empty sella may be explained by pituitary tumor degeneration secondary to apoplexies.

\section{REFERENCIAS}

1. BERGLAND, R. M.; RAY, B. S. \& TORACK, R. M. - Anatomical variations in the pituitary gland and adjacent structures in 225 human autopsy cases. J. Neurosurg. 28:93, 1968.

2. BERNASCONI, V.; GIOVANELli, M. A. \& PAPO, I. - Primary empty sella. J. Neurosurg. 36:157, 1972 .

3. BRISMAN, R.; HUGHES, J. E. O. \& MOUNT, L. A. - Cerebrospinal fluid rhinorrhea and the empty sella. J. Neurosurg. 31:538, 1969.

4. BROUGHAM, M.; HEUSNER, A. P. \& ADAMS, R. R. - Acute degenerative changes in adenomas of the pituitary body with special reference to pituitary apoplexy. J. Neurosurg. 7:421, 1950.

5. CANESCHI, S.; GIOVANELLI, M. \& PERRIA, C. - Rinoliquorree non traumatiche. G. Psichiat. Neuropat. 95:187, 1967.

6. LEE, W. M. \& ADAMS, J. E. - The empty sella syndrome. J. Neurosurg. 28: 351, 1968.

7. MORTARA, R. \& NORRELL, H. - Consequences of a deficient sellar diaphragm. J. Neurosurg. 32:565, 1970.

8. OBRADOR, S. - The empty sella and some related syndromes. J. Neurosurg. 36:162, 1972.

9. RAY, B. S. \& BERGLAND, M. R. - Cerebrospinal fluid fistula. Clinical aspects, techniques of localization and methods of closure. J. Neurosurg. 30:399, 1969.

10. ROVIT, R. L.; SCHECHTER, M. M. \& NELSON, K. - Spontaneous "highpressure" cerebrospinal rhinorrhea due to lesions obstructing flow of cerebrospinal fluid. J. Neurosurg. 30:406, 1969. 
E R R A T A

No trabalho "Tratamento microcirúrgico de aneurismas da artéria comunicante anterior", de autoria do Dr. Luiz Carlos Mendes Faleiro e col., publicado no exemplar de dezembro-1973 desta revista, ocorreu desagradável lapso da revisão pois a figura 1 , na página 268 , foi colocada em posição invertida, ficando para baixo o lado que devia estar para cima e para a esquerda a parte que devia estar à direita. A simples inspecção permitirá aos leitores desta revista, todo afeitos à análise e interpretação de chapas angiográficas, corrigir esse cochilo da revisão.

Também no trabalho "Complicações neurológicas da cirurgia cardíaca", de autoria dos Drs. Lineu Cesar Werneck e Danton R. Rocha Loures, publicado no mesmo exemplar de dezembro-1973, a revisão funcionou mal, deixando escapar três erros tipográficos graves:

1) na página 271, penúltima linha, onde está dito "Destes 320 pacientes, 310 foram...", deve ser corrigido para "Destes 320 pacientes, 210 foram...";

2) na página 276 há erro na designação de um subcapítulo pois onde está "LESÕES ISQUEMICAS COM OCLUSÃO OCULAR" deve ser corrigido para "LESÓES ISQUEMICAS COM OCLUSÃO ARTERIAL";

3) o mesmo erro acima assinalado ocorreu na página 278 na qual a designação do subcapítulo "LESÕES ISQUÊMICAS SEM OCLUSÃO OCULAR" deve ser corrigido para "LESÕES ISQUÊMICAS SEM OCLUSÃO ARTERIAL".

O Editor da revista pede, aos autores e aos leitores, escusas por estes lapsos de revisão, agradecendo aos Autores o cuidado de reler o trabalho tipograficamente terminado. 